\title{
Learning visual skills from your environment: A rhizomatic m-learning approach.
}

\author{
Matthew Guinibert \\ Auckland University of Technology \\ matt.guinibert@aut.ac.nz
}

Submission Type: Brief presentation (20mins +10 minsQ\&A)

Keywords: mlearning, rhizomatic learning, visual literacy

\begin{abstract}
:
Due to the recent widespread adoption of technologies such as the internet, social media, and digital image capture and creation, the average person today needs to decode and process information from many different formats and media to fully participate in the contemporary world (Tertiary Education Commission, 2008; Hanifan, 2008). This study aimed to address this need by exploring how the visuals one encounters every day can be leveraged as opportunities for learning visual literacy. The aim operates on the presupposition that a person is surrounded by visuals in their everyday environment which they could potentially analyse to deepen their knowledge. However, learning from visuals in one's environment is often beyond the capabilities of novice learners, due to a lack of learning support in this informal learning setting. Therefore, this study propositioned a learning model of visual skills based on mobile learning (m-learning) and rhizomatic learning.
\end{abstract}

M-learning allows learners to learn in multiple contexts, across time and space, through social and content interactions, using personal electronic devices so that learning can be available everywhere and every time (Crompton, 2013; Georgiev, Georgieva, \& Smrikarov, 2004). This leads to learning that can be more situated in a learner's surroundings (Gikas \& Grant, 2013), which is an attractive proposition when considering how learners can learn from life's everyday imagery when they are separated from traditional learning support.

In rhizomatic learning, the curriculum is not predefined by experts or teachers, instead, "community acts as the curriculum, spontaneously shaping, constructing, and reconstructing itself and the subject of its learning in the same way that the rhizome responds to changing environmental conditions" (Cormier, 2008, p. 5). In this way, rhizomatic learning communities can provide crowd-sourced peer support as ubiquitous as imagery is.

The learning model proposed in this presentation was arrived at by utilising a practice-based research approach. The learning model was implemented and tested as prototype for an app. Usability testing and interviews were used to qualitatively evaluate the prototype, as well as the underlying learning model. The outcomes of the study demonstrate that visual literacy can be achieved by novice learners from contingent learning encounters in informal learning environments through collaboration and by providing context-aware learning support. The presentation will focus on the outcome of the study, which is the learning model and its pedagogical assumptions.

\section{References:}

Cormier, D, (2008) Rhizomatic Education: Community as Curriculum. Innovate: Journal of Online Education, 4(5), article 2. Retrieved from https://nsuworks.nova.edu/innovate/vol4/iss5/2

Crompton, H. (2013). A historical overview of m-learning: Toward learner-centered education. In Zane L. Berge, and Lin Muilenburg (Ed.), Handbook of Mobile Education (pp. 3-14). New York, NY: Routledge.

Georgiev, T., Georgieva, E., \& Smrikarov, A. (2004). M-learning: A new stage of e-learning. In International Conference on Computer Systems and Technologies-CompSysTech (pp. 1-5). Retrieved from http://ecet.ecs.uni-ruse.bg/cst04/Docs/sIV/428.pdf

Gikas, J., \& Grant, M. M. (2013). Mobile computing devices in higher education: Student perspectives on learning with cellphones, smartphones \& social media. The Internet and Higher Education, 19, 18-26. doi:10.1016/j.iheduc.2013.06.002 
Hanifan, T. (2008). It's more than reading and writing: The nature and extent of adult's literacy issues. In John Benseman, Alison Sutton and Diana Coben (Eds.), Facing the challenge: Foundation learning for adults in Aotearoa New Zealand (pp. 125-135). Auckland, New Zealand: Dunmore Pub.

Tertiary Education Commission. (2008). Learning progressions: For adult literacy. Wellington, New Zealand: Learning Media. Retrieved from https://ako.ac.nz/knowledge-centre/learning-progressions-for-adultliteracy/ 